\title{
Protein Digestion in vivo: Peptides and Free Amino Acids in the Jejunum of Rats Fed Different Dietary Proteins
}

\author{
M. Raghunath, * S.N. Murthy, and B.S. Narasinga Rao \\ National Institute of Nutrition, Indian Council of Medical Research, \\ Jamai Osmania P.O., Hyderabad - 500 007, India
}

(Received June 30, 1987)

\begin{abstract}
Summary To understand the relevance of peptide release and absorption during protein digestion to its quality, digestibility of a few animal (AP) and plant proteins (PP) was studied in trained rats. Some differences were observed between proteins in their digestion in vivo and absorption (as assessed by recovery of fed nitrogen). We observed that rats fed AP diets had a greater proportion of peptides (total, large (P1) and small (P2) including dipeptides) in their jejunal luminal supernatants than those fed PP diets, which had a greater proportion of free amino acids (AA). AA fractions always had a higher essential amino acid (EAA) content than peptide fractions; and among peptide fractions, the P1 fraction had a greater content of EAAs than the P2 fraction. Protein quality was correlated positively with the proportion of peptides (total, P1, P2, and dipeptides) in the jejunal luminal supernatants and negatively with that of AAs. Incorporation of some of these in vivo digestion indices increased the correlation between chemical and animal growth indices of protein quality, suggesting their relevance to protein nutritional quality.
\end{abstract}

Key Words: protein digestion, peptides, amino acids, jejunal contents, protein quality

Digestion and absorption of dietary proteins in the mammalian gastrointestinal tract is not yet understood completely, specially with reference to the types of and quantity of each type of digestion product released during the terminal stages of protein digestion in vivo. Some differences have been observed in the quantities of large peptides (P1), small peptides (P2) including dipeptides, and free amino acids (AA) released during the sequential enzymatic digestion in vitro of some APs and PPs [1]. Also a significant correlation was observed between protein quality and some in vitro protein digestion indices [2]. In view of the pos-

\footnotetext{
*To whom correspondence should be addressed.
} 
sible significant contribution of peptide absorption to the absorption of the protein digestion products and its possible nutritional significance [3, 4], release of peptides during digestion of dietary proteins in vivo is of great nutritional significance. Further, there are very few studies which have analysed the peptide release during protein digestion in vivo. Since the rat has been widely used for such studies, profiles of peptides and free AAs in the jejunal luminal contents of rats fed a few dietary proteins were determined.

\section{MATERIALS AND METHODS}

Materials. $\alpha$-Lactalbumin ( $\alpha$-Lact), hen egg whites (EW), wheat gluten and corn zein were purchased from Sigma Chemical Co., USA. Goat meat protein isolate (GMPI) was supplied gratis by Central Food Technological Research Institute (CFTRI), Mysore (India). 1-Fluoro-2,4-dinitrobenzene (FDNB) and Sephadex G-25 (medium) were from Sigma and Pharmacia, Sweden, respectively. Standard amino acid mixture and ninhydrin were obtained from Pierce Chemical Co., USA, while lithium citrate buffers and lithium hydroxide were from Beckman Instruments Co., USA. All other chemicals used were of analytical grade and procured locally.

Animal feeding/training of rats. Adult female rats (CFY/NIN strain), weighing 200-300 g, were randomly divided into groups of eight animals each based on their body weight. They were trained for 10-15 days to consume their total daily diet in $1 \mathrm{~h}$ between 9 and $10 \mathrm{a} . \mathrm{m}$. every day, according to the method of Peraino et al. [5]. Though the animals lost weight initially, most of them regained most of their weight by 10-15 days of training and were then used for the experiment. On the day of the experiment, each rat was offered $5 \mathrm{~g}$ of an experimental diet $(20 \%$ protein) of its respective group, in a 30 -min feeding period between 9 and 10 a.m. and the actual diet intake was recorded. All other ingredients (mineral mixture, vitamin mixture, and refined groundnut oil) being in similar proportions, the training diet contained $15 \%$ sucrose and $55 \%$ corn starch, whereas in experimental diets their proportions were $35 \%$ each. The proportion of sucrose in the experimental diet was increased to enhance its acceptability by the rats.

Optimum time to sacrifice rats after feeding. The appropriate time for killing the animals was determined using a group of rats trained on the EW diet. Trained rats were fed $5 \mathrm{~g}$ of experimental EW diet, and three of them were sacrificed at each time point, viz., $0,1,2,3$, and $4 \mathrm{~h}$ after the end of the feeding period. Their jejunal luminal contents were collected and analysed for free and total amino nitrogen (AN) (in $6 \mathrm{~N} \mathrm{HCl}$ hydrolysates) contents. The $\mathrm{AN}$ values were found to be maximal $2 \mathrm{~h}$ after feeding, whereafter they decreased. Hence, in the subsequent studies where different protein sources were tested, rats were killed $2 \mathrm{~h}$ after feeding the experimental diet.

Protein digestion products in the jejunal luminal contents of rats fed different proteins. Groups of rats trained on diets based on different proteins were offered 
$5 \mathrm{~g}$ of their respective experimental diets during a 30 -min feeding period. The amount of diet consumed was recorded and the animals were sacrificed $2 \mathrm{~h}$ following the feeding period. Contents of their stomach and jejunal (proximal half of the small intestine) lumens were flushed with ice-cold normal saline into ice-cold beakers, taking care to see that no pieces of tissue were in the wash. Contents from four animals fed the same diet were pooled for further analysis. The pooled contents were made up to a known volume with ice-cold saline and centrifuged at 2,500 $\mathrm{rpm}$ for $10 \mathrm{~min}$ at $4^{\circ} \mathrm{C}$. The insoluble fractions (residues) were homogenized in known volumes of water and these homogenates and the jejunal luminal supernatants were stored frozen at $-20^{\circ} \mathrm{C}$ till analysed.

Similarly, the protein digestion products in the gastric and jejunal luminal contents of rats fed a protein-free diet were analysed to determine the endogenous profile of endogenous proteinaceous products in the stomach and jejunum.

Analyses of contents. Total nitrogen (N) content of the diets, residue homogenates, and luminal supernatants were determined by the microkjeldahl method. Free and total AN contents of the jejunal luminal supernatants were determined by the FDNB method of Goodwin [6].

The jejunal luminal supernatants were lyophilysed and redissolved in a minimum volume of water; then an aliquot containing a known amount of AN was loaded onto a column of copper Sephadex G-25 and eluted according to the method of Fazakerley and Best [7]. The peptide and free amino acid fractions obtained were freed of copper as described elsewhere [1]. Their free and total AN contents were determined, from which the approximate average size of peptides in the peptide fractions was calculated as follows:

Approximate average size of peptides $=\frac{\begin{array}{l}\text { AN content of the fraction after acid } \\ \text { hydrolysis }\end{array}}{\begin{array}{l}\text { AN content of the fraction before hydrol- } \\ \text { ysis }\end{array}}$

The amino acid composition of the different fractions was determined with an automatic AA analyser and the dipeptide content of the peptide fractions, by the biuret method [8].

\section{RESULTS AND DISCUSSION}

The range of proteins selected was such that they represented the two major classes of proteins, viz., animal (AP) and plant proteins (PP), which differ widely in their nutritional quality. It should be mentioned at the outset that though some differences were observed between the two pooled samples obtained from animals fed the same protein diet, the trend of observations was similar in both the samples; and, hence, average of the two pooled samples were used for comparisons among different proteins. 


\section{Nitrogen intake of, and recovery from, rats fed different diets}

Intake of dietary nitrogen $(\mathrm{N})$ (of four rats fed the same diet) ranged between 450 and $560 \mathrm{mg}$ in rats fed diets based on GMPI, EW, $\alpha$-Lact and gluten, while the intake was lower $(350 \mathrm{mg})$ with the zein diet, due probably to poorer acceptability of the zein one. Dietary $\mathrm{N}$ which could not be recovered in the contents of stomach and jejunum was considered as $\mathrm{N}$ absorbed, and it had values of 37.8, 69.8, 55.7, 52.0, and 59.5 per cent in rats fed diets based on GMPI, EW, $\alpha$-Lact, gluten, and zein, respectively.

Values of digestibility (sum of percentages of fed $\mathrm{N}$ in the soluble fraction and that absorbed) of GMPI, EW, $\alpha$-Lact, gluten, and zein diets were 45.2, 95.6, $65.3,68.7$, and 66.1 , respectively at $2 \mathrm{~h}$ after feeding. These values corresponded well with their respective values from in vitro enzymatic digestion [1]. Interestingly both in vitro and in vivo, GMPI had the least digestibility (45.2) and EW the highest (95.6). The digestibility of other proteins was around $65.70 \%$.

Of the $\mathrm{N}$ recovered, $90 \%$ was in the stomach contents and the rest, in the jejunal lumen, irrespective of the protein fed. In stomach contents, the greater proportion of $\mathrm{N}(70-90 \%)$ was in the residue (exception EW: $16 \%$ ) than in the supernatant $(10-30 \%)$. However, the proportions were almost reversed between the residue and supernatant fractions in the case of jejunal luminal contents. There were some differences between rats fed different proteins in this respect, which observations are in agreement with those of some earlier reports [9, 10], and indicate differences between proteins in their digestion and absorption in vivo.

We observed that in rats fed a protein-free diet the endogenous $\mathrm{N}$ contributed around 7 and 49 per cent, respectively to the total $\mathrm{N}$ of stomach and jejunal luminal contents. These observations agree well with those of Chen et al. [11], who also observed that the jejunal lumen contains a significant amount of endogenous $\mathrm{N}$.

Amino nitrogen content of jejunal luminal supernatants and its distribution among different fractions

Representative elution profiles, from columns of Cu-Sephadex G-25, of jejunal luminal supernatants of rats fed different diets are given in Fig. 1. In all the samples there were two peptide fractions, P1 and P2, and a free AA fraction. Recovery of $\mathrm{AN}$ of the samples loaded onto $\mathrm{Cu}$-Sephadex $\mathrm{G}-25$ columns was in the range of $70-75 \%$, and these values were lower than those observed with in vitro digests. Though the reasons for the poor recovery are not clear, it could be due to the presence in jejunal luminal supernatants of substances other than protein digestion products, such as carbohydrates, fatty acids, etc., which might interfere with separations.

The approximate average size of peptides in the different peptide fractions obtained and the percentage distribution of recovered AN among different fractions are given in Table 1. In general, the P1 (large peptide) fractions contained peptides of 3-5 AA residues per peptide on an average, while in P2 (small peptide) frac- 

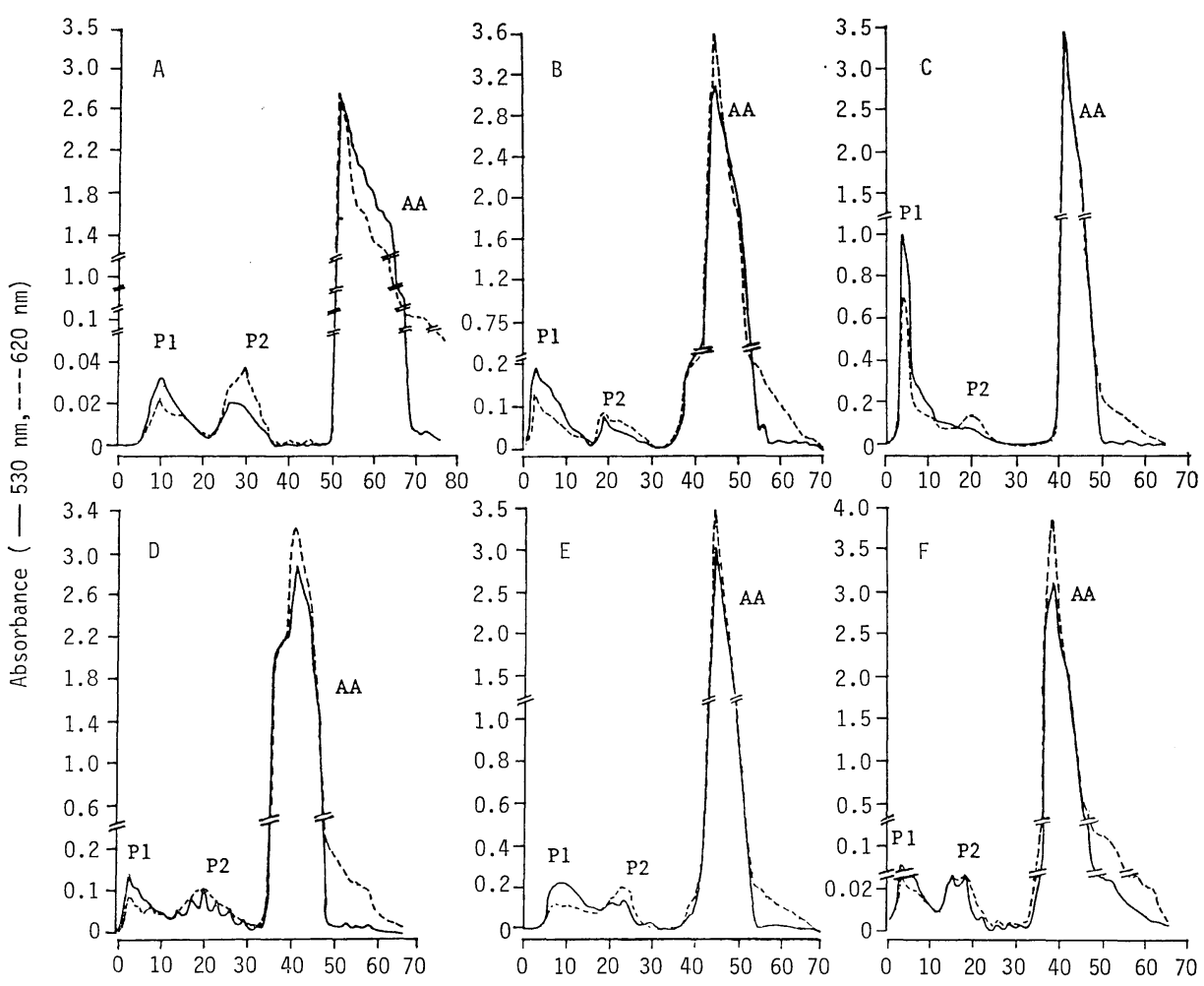

Fraction Number

Fig. 1. Elution profiles from columns of copper-Sephadex G-25 of jejunal luminal supernatants of rats fed different dietary proteins. A, Protein-free; B, GMPI; C, EW; D, $\alpha$-Lact; E, gluten; F, zein.

Table 1. Percentage distribution of recovered AN among different fractions and the approximate size of peptides in different peptide fractions.

\begin{tabular}{lcccc}
\hline Diet fed & P1 & P2 & P1+P2 & Free AA \\
\hline Animal proteins & $37.7(5.14)$ & $28.5(3.60)$ & 66.2 & 33.8 \\
$\quad$ GMPI & $46.8(5.16)$ & $25.2(1.90)$ & 72.0 & 28.0 \\
EW & $9.3(3.07)$ & $22.7(1.36)$ & 32.0 & 68.0 \\
$\alpha$-Lact & $31.3 \pm 19.56$ & $25.5 \pm 2.91$ & $56.7 \pm 21.62$ & $43.3 \pm 21.62$ \\
Mean \pm SD & $(4.46 \pm 1.201)$ & $(2.29 \pm 1.169)$ & & \\
& & & & \\
Plant proteins & $31.3(4.23)$ & $24.7(2.01)$ & 56.0 & 44.0 \\
$\quad$ Gluten & $9.9(5.05)$ & $17.0(2.98)$ & 26.9 & 73.1 \\
Zein & $20.6 \pm 15.13$ & $20.9 \pm 5.45$ & $41.5 \pm 20.58$ & $58.6 \pm 20.58$ \\
Mean \pm SD & $(4.64 \pm 0.579)$ & $(2.50 \pm 0.686)$ & & \\
Protein-free & $24.5^{\mathrm{a}}(6.17)$ & $39.8^{\mathrm{a}}(4.38)$ & $64.3^{\mathrm{a}}$ & 35.7 \\
\hline
\end{tabular}

a Values given are total $\mathrm{AN}$ of the fraction/total $\mathrm{AN}$ recovered from $\mathrm{Cu}-\mathrm{Sephadex} \mathrm{G}-25$ column $\times 100$.

Figures in parenthesis are approximate average size of peptides in the fraction under study (for details refer to text). All values are means of two pooled samples.

Vol. 3, No. 3, 1987 
tions the size was 1.4-3.6 AAs per peptide, indicating differences between proteins in the type of peptides released during their digestion in vivo. Further, these values were somewhat lower than those observed during protein digestion in vitro [1], indicating differences between protein digestion in vitro and in vivo.

In rats fed GMPI, EW and gluten diets, $56-72 \%$ of the recovered AN was in peptides and the rest, in the free AA fraction, while in rats fed $\alpha$-lactalbumin and zein their proportions were $30 \%$ in peptides and $70 \%$ in free AAs, respectively. Further, the large peptide fraction, P1, was in greater proportion in the former group of rats; while in the latter, the small peptide fraction, P2, was in greater proportion. Nevertheless, the mean values of proportions of recovered AN present as $\mathrm{P} 1$ or $\mathrm{P} 2$ (and also as $\mathrm{P} 1+\mathrm{P} 2$ ) were greater in rats fed AP diets than in those fed PP diets, the latter having the greater proportion of free AAs. These differences, though not significant statistically, nevertheless indicate differences between proteins in the types of and quantities of each type of digestion product they yield during their digestion in vivo and are in agreement with those reported earlier [11, 12].

\section{Dipeptide content of the peptide fractions}

As one would expect, in all animals fed different protein diets, the small peptide fraction (P2) contained greater proportion of dipeptides than the large peptide fraction (P1) (Table 2). However, differences in the mean values of the dipeptide content of $\mathrm{P} 1$ and $\mathrm{P} 2$ fractions from rats fed AP or PP diets were not significant. In general, dipeptides accounted for $10-38 \%$ of the total AN content of the different jejunal supernatants and the mean values were higher in animals fed AP diets than in those fed PP diets. Further, the values obtained here are in good

Table 2. Dipeptide content of the peptide fractions obtained from jejunal luminal supernatants of rats fed different protein diets.

\begin{tabular}{|c|c|c|c|}
\hline \multirow[b]{2}{*}{ Diet fed } & \multicolumn{3}{|c|}{$\%$ of dipeptide total amino nitrogen in } \\
\hline & $\mathrm{P} 1$ & P2 & $\begin{array}{c}\text { Jejunal } \\
\text { supernatant }\end{array}$ \\
\hline \multicolumn{4}{|l|}{ Animal proteins } \\
\hline GMPI & $22.6^{\mathrm{a}}$ & 92.9 & 31.1 \\
\hline EW & 31.8 & 93.5 & 37.7 \\
\hline$\alpha$-Lact & 48.6 & 54.6 & 9.9 \\
\hline Mean $\pm S D$ & $34.3 \pm 13.18$ & $80.3 \pm 22.29$ & $26.2 \pm 14.54$ \\
\hline \multicolumn{4}{|l|}{ Plant proteins } \\
\hline Gluten & 9.3 & 81.8 & 16.1 \\
\hline Zein & 54.6 & 89.2 & 11.8 \\
\hline Mean $\pm S D$ & $31.9 \pm 32.03$ & $85.5 \pm 5.26$ & $13.9 \pm 3.04$ \\
\hline Protein-free & $74.9^{\mathrm{a}}$ & 37.2 & 33.2 \\
\hline${ }^{\mathrm{a}} \mathrm{V}$ & $\begin{array}{l}\text { ue to dipeptide } \\
\mathrm{N} \text { content of }\end{array}$ & $\frac{\text { fraction }}{\text { tion }} \times$ & are means \\
\hline
\end{tabular}


agreement with the in vitro digestion values reported by us earlier [1]. However, it is intriguing that, in jejunal supernatants of rats fed a good quality protein like $\alpha$-Lact, dipeptides constituted only $10 \%$ of the total AN (the lowest of all). This could be due to the rapid absorption of peptides (including dipeptides) released during the digestion of $\alpha$-Lact in vivo, leaving behind only small amounts of them $2 \mathrm{~h}$ after the animals had eaten. However, this argument can not explain satisfactorily the low proportion of dipeptides $(12 \%)$ found in the jejunal luminal supernatants of rats fed a poor quality protein like zein. Further studies are therefore needed to explain these types of discrepancies in peptide release and absorption.

Release of essential amino acids and non-essential amino acids as peptides and free amino acids

A close look at the mean values of percentage distribution of recovered EAAs and NEAAs among the P1, P2, and AA fractions calculated from their amino acid composition data indicates that rats fed AP diets contained in their jejunal luminal supernatants a greater proportion of both EAAs and NEAAs (50 and 57 $\%$, respectively) as peptides than those fed PP diets (36 and $41 \%$, respectively)

Table 3. Percentage distribution of recovered essential amino acids and non-essential amino acids of jejunal luminal supernatants in different fractions.

\begin{tabular}{|c|c|c|c|}
\hline \multirow{2}{*}{ Diet fed } & \multicolumn{3}{|c|}{ Percent of EAA recovered present in } \\
\hline & P1 fraction & $\mathrm{P} 2$ fraction & AA fraction \\
\hline \multicolumn{4}{|l|}{ Animal proteins } \\
\hline GMPI & 34.6 & 19.9 & 45.6 \\
\hline EW & 45.6 & 18.7 & 35.8 \\
\hline$\alpha$-Lact & 18.7 & 13.7 & 67.7 \\
\hline Mean $\pm S D$ & $32.9 \pm 13.36$ & $17.4 \pm 5.47$ & $49.7 \pm 15.26$ \\
\hline \multicolumn{4}{|l|}{ Plant proteins } \\
\hline Gluten & 34.1 & 14.1 & 51.8 \\
\hline Zein & 19.9 & 4.1 & 76.0 \\
\hline Mean \pm SD & $27.0 \pm 8.34$ & $9.1 \pm 5.82$ & $63.9 \pm 13.91$ \\
\hline Protein-free & 30.8 & 24.5 & 44.7 \\
\hline \multirow{2}{*}{ Diet fed } & \multicolumn{3}{|c|}{ Percent of NEAA recovered present in } \\
\hline & P1 fraction & P2 fraction & AA fraction \\
\hline \multicolumn{4}{|l|}{ Animal proteins } \\
\hline GMPI & 36.9 & 22.5 & 40.7 \\
\hline EW & 52.1 & 25.8 & 22.2 \\
\hline$\alpha$-Lact & 13.1 & 19.4 & 67.5 \\
\hline Mean $\pm \mathrm{SD}$ & $34.0 \pm 17.79$ & $22.6 \pm 5.41$ & $43.4 \pm 20.52$ \\
\hline \multicolumn{4}{|l|}{ Plant proteins } \\
\hline Glutein & 33.1 & 22.6 & 44.4 \\
\hline Zein & 16.0 & 9.0 & 75.0 \\
\hline Mean \pm SD & $24.6 \pm 10.46$ & $15.8 \pm 8.00$ & $59.7 \pm 17.87$ \\
\hline Protein-free & 29.9 & 35.2 & 34.9 \\
\hline
\end{tabular}

All values given are means of two pooled samples.

Vol. 3, No. 3, 1987 
Table 4. Total content and total essential amino acids/total non-essential amino acids ratios of jejunal luminal supernatants of rats fed different proteins and their peptide and free amino acids fractions.

\begin{tabular}{|c|c|c|c|c|c|c|c|c|}
\hline & \multicolumn{2}{|c|}{ Jejunal supernatant } & \multicolumn{2}{|c|}{ P1 fraction } & \multicolumn{2}{|c|}{$\mathrm{P} 2$ fraction } & \multicolumn{2}{|c|}{ Free AA fraction } \\
\hline & $\mathrm{a}$ & $\mathrm{b}$ & $\mathrm{a}$ & $\mathrm{b}$ & $\mathrm{a}$ & b & $\mathrm{a}$ & $\mathrm{b}$ \\
\hline \multicolumn{9}{|c|}{ Animal proteins } \\
\hline GMPI & 275 & 0.487 & 189 & 0.350 & 178 & 0.494 & 313 & 0.847 \\
\hline EW & 336 & 0.742 & 17.1 & 0.532 & 12.1 & 0.437 & 21.6 & 1.192 \\
\hline$\alpha$-Lact & 259 & 0.719 & 18.8 & 0.397 & 9.5 & 0.309 & 21.5 & 0.753 \\
\hline \multicolumn{9}{|c|}{ Plant proteins } \\
\hline Gluten & 204 & 0.371 & 16.6 & 0.381 & 8.9 & 0.264 & 18.4 & 0.582 \\
\hline Zein & 266 & 0.638 & 14.5 & 0.424 & 3.8 & 0.233 & 19.1 & 0.730 \\
\hline Protein-free & 278 & 0.576 & 199 & 0.419 & 156 & 0.480 & 304 & 1.010 \\
\hline
\end{tabular}

a, Total EAA content of the sample expressed as mmol of total EAAs per mol of total AN in the sample. b, The ratio of total EAA/total NEAA of the sample under study. All values are means of two pooled samples.

(Tabel 3). The latter had greater proportions of both EAAs $(64 \%)$ and NEAAs $(59 \%)$ as free AAs compared with the former (50\% and $43 \%$, respectively). Unlike in vitro digests, in jejunal luminal supernatants, among peptide fractions the large peptide fraction (P1) contained a greater proportion of both EAAs and NEAAs than the small peptide fraction (P2), indicating some differences between protein digestion in vitro and in vivo in terms of release of EAAs and NEAAs as large peptides, small peptides and free AAs.

Amino acid composition analyses of the jejunal luminal supernatants and their constituent peptide and free AA fractions further indicated differences in the contents of different AAs in a given fraction and also in the content of the same AA in different samples. Total EAA content and total EAA/total NEAA (ratio), the two indices used to assess the relative AA compositions of different samples, indicated the P1 fraction to be better than the P2 in most instances (Table 4), except in GMPI-fed rats, where the ratio but not total EAA content showed the P2 fraction to be better than the P1. Similar to that observed during protein digestion in vitro, both indices put the free AA fractions above the peptides. While P1 fractions did not differ much in their ratios between rats fed AP and PP diets, P2 of PP-fed rats had lower ratios than P2 of AP-fed rats and P1 of PP-fed rats. These observations are not in full agreement with our observations on in vitro protein digestion. Nevertheless, they indicate differences in the AA composition of digestion products released during protein digestion in vivo.

Correlation between protein quality and some indices of protein digestion in vivo

We observed that simple correlation coefficients between some in vivo protein digestion indices and two indices of protein quality, relative protein value (RPV) and integrated essential amino acid index (EAAI), were almost the same in most cases (Table 5). There was a significant positive correlation between dipeptide content 
Table 5. Correlation between protein quality and release of peptides including dipeptides and amino acids during protein digestion in vivo.

\begin{tabular}{|c|c|c|c|c|c|c|c|}
\hline & \multicolumn{3}{|c|}{ Dipeptide content of ${ }^{a}$} & \multicolumn{4}{|c|}{ Total AN content of $\mathrm{b}$} \\
\hline & $\begin{array}{c}\text { P1 } \\
\text { fraction }\end{array}$ & $\begin{array}{c}\mathrm{P} 2 \\
\text { fraction }\end{array}$ & $\begin{array}{c}\text { Jejunal } \\
\text { upernatant }\end{array}$ & $\begin{array}{c}\mathrm{P} 1 \\
\text { fraction }\end{array}$ & $\begin{array}{c}\text { P2 } \\
\text { fraction }\end{array}$ & $\mathbf{P} 1+\mathbf{P} 2$ & AA \\
\hline PV & $9916 * *$ & & & & & $35^{*}$ & \\
\hline Lact) & 0.9062 & 0.8954 & $0.9921^{* *}$ & 0.9135 & $0.9669 *$ & .9360 & 269 \\
\hline \multicolumn{8}{|c|}{$\begin{array}{l}\text { Actual dipeptide AN content (after correction for a constant diet intake and protein-free diet } \\
\text { values) was used for the correlation analysis. b Actual total AN content (after correction for } \\
\text { a constant diet intake and protein-free diet values) was used for the correlation analysis. } * p< \\
0.05 ; * * p<0.01 \\
\text { Simple correlation coefficient between RPV and EAAI: } r=0.9158, r^{2}=83.5 \% \text {. } \\
\text { Multiple correlation coefficient between RPV and EAAI: i) By incorporating dipeptide } \\
\text { content of jejunal supernatant: } r=0.9973, r^{2}=99.5 \% \text { ii) By incorporating total amino } \\
\text { nitrogen content of the peptides in the jejunal supernatant: } r=0.9554, r^{2}=92.3 \%, \alpha \text {-Lact- } \\
\text { albumin values were not used for correlation analysis. }\end{array}$} \\
\hline
\end{tabular}

of large peptide fraction P1 and of jejunal supernatants on one hand and the protein quality on the other. Though the $r$ value was high between dipeptide content of P2 fraction and protein quality, it lacked significance. Similar values of correlation coefficients were obtained between protein quality indices and total AN content of peptide fractions ( $\mathrm{P} 1, \mathrm{P} 2$, and also total peptides). Interestingly, protein quality showed a negative correlation with the total $\mathrm{AN}$ present as free AAs in the jejunal supernatants. Though some of these correlations are not significant statistically, they nevertheless indicate that in the jejunum of rats fed good quality proteins there were more peptides including dipeptides than in rats fed poor quality ones that had more free AAs. This, to our knowledge, is something new and goes against the classical hypothesis of protein digestion and absorption of AAs. Further, these correlations are on similar lines as those observed by us [2] and also by Amiot et al. [13] during in vitro enzymatic digestion of proteins. In this respect in vivo and in vitro protein digestion indices appear to be somewhat similar although some differences exist in the absolute values of digestion indices themselves.

Incorporation of some of the in vivo protein digestion indices, such as dipeptide content of jejunal supernatant, proportion of the total peptides released, or the release of EAAs as peptides (but not that of NEAAs), increased the correlation between EAAI (a chemical index) and RPV (animal growth index) of protein quality (i.e., the $r$ value increased from 0.9158 to 0.9522 , or $r^{2}$ value from 83.5 to $90.7 \%$ ). These multiple correlation analyses thus indicate the probable significance of the release of AAs (more so the EAAs) as peptides and specifically as dipeptides during protein digestion in vivo in the determination of protein nutritional quality.

The exact significance of these correlations can not be assessed, in view of

Vol. 3, No. 3, 1987 
the dynamic situation that obtains in vivo. Nevertheless, we can conclude from the observations presented here that differences do exist between proteins in their digestion in vivo with reference to the release of their AAs as peptides and free AAs, and that some of the parameters of in vivo digestion are relevant to protein nutritional quality.

The valuable technical assistance of Ms. S. Hemalatha is gratefully acknowledged.

\section{REFERENCES}

1. Raghunath, M., and Narasinga Rao, B.S. (1984): Release of peptides and amino acids from dietary proteins during sequential enzymatic digestion in vitro with pepsin, pancreatin + trypsin and erepsin. Food Chem., 15, 285-307.

2. Raghunath, M., and Narasinga Rao, B.S. (1984): Relationship between relative protein value and some in vitro indices of protein quality. J. Biosci., 6, 655-661.

3. Silk, D.B.A., Hegarty, J.E., Fairclough, P.D., and Clark, M.L. (1982): Characterization and nutritional significance of peptide transport in man. Ann. Nutr. Metab., 26, 337-352.

4. Gardner, M.L.G., Lindbald, B.S., Burston, D., and Matthews, D.M. (1983): Transmucosal passage of intact peptides in the guinea pig small intestine in vitro: a reappraisal. Clin. Sci., 64, 433-439.

5. Peraino, C., Rogers, Q.R., Yoshida, M., Chen, M.L., and Harper, A.E. (1959): Observations on protein digestion in vivo II. Dietary factors affecting the rate of disappearance of casein from the gastrointestinal tract. Can. J. Biochem. Physiol., 37, 1475-1492.

6. Goodwin, J.F. (1969): The colorimetric estimation of plasma amino nitrogen with FDNB. Clin. Chem., 14, 1080-1090.

7. Fazakerley, S., and Best, D.R. (1965): Separation of amino acids as copper chelates from amino acid, protein and peptide mixtures. Anal. Biochem., 12, 290-295.

8. Raghunath, M., and Narasinga Rao, B.S. (1983): Determination of dipeptides in peptide mixtures using a simple biuret method. Indian J. Biochem. Biophys., 20, 149-153.

9. Curtis, K.J., Gaines, H.D., and Kim, Y.S. (1978): Protein digestion and absorption in rats with pancreatic duct oclusion. Gastroenterology, 74, 1271-1276.

10. Crane, C.W. (1964): Studies on the absorption of ${ }^{15} \mathrm{~N}$-labelled yeast protein in normal subjects and patients with malabsorption, in The Role of the Gastrointestinal Tract in Protein Metabolism, ed. by Munro, H.N., Blackwell Scientific Publishers, Oxford, pp. 333-347.

11. Chen, M.L., Rogers, Q.R., and Harper, A.E. (1962): Observations on protein digestion in vivo. IV. Further observations on the gastrointestinal contents of rats fed different dietary proteins. J. Nutr., 76, 235-239.

12. Chung, Y.C., Kim, Y.S., Shadchehr, A., Garrido, A., MacGregor, I.L., and Sleissenger, M.H. (1979): Protein digestion and absorption in the human small intestine. Gastroenterology, 76, 1415-1421.

13. Amiot, J., Brisson, G.J., Delisle, J., Goulet, G., Savoie, L., and Jones, J.D. (1981): Nitrogenous products released by in vitro enzymatic hydrolysis of food proteins. Nutr. Rep. Int., 24, 513-529. 